\section{Photosynthesis of Amino-Acids}

IT has been observed in this laboratory that when aqueous mixtures of dicarboxylic or monocarboxylic acids and certain ammonium salts are irradiated with ultra-violet light, certain amino-acids are obtained.

A cold quartz ultra-violet lamp giving 86 per cent of its output at about $2537 \mathrm{~A}$. was used for irradiated mixtures of succinic, maleic, propionic and acetic acid with a number of ammonium salts. These mixtures were 0.1 molar both in organic acid and ammonium salt. The irradiation was continued in each case for $24 \mathrm{hr}$., the area of the irradiated solutions being $44 \mathrm{~cm} .{ }^{2}$, and the radiation intensity 7,500 microwatts $\mathrm{cm}^{2}$ at the surface of the liquid.

Of all the ammonium compounds investigated only ammonia and ammonium carbonate were active, and of the acids only succinic, maleic and propionic acid gave rise to amino-acids.

An absorption curve in the ultra-violet region, with a peak at $2750 \mathrm{~A}$., was obtained for succinic acid irradiated in presence of ammonia or ammonium carbonate. This indicates the presence of a $\mathrm{C}=\mathrm{O}$ group, which was confirmed by positive tests for aliphatic aldehyde; tests for ketone were negative. Aldehydes were not detected after irradiation of maleic and propionic acids.

The irradiated solutions were evaporated to dryness, the residue taken up with acidified acetone (in 1 per cent hydrochloric acid) for desalting, the acetone was evaporated and the residue dissolved in a few drops of isopropylic alcohol $(10$ per cent in water).

Paper chromatograms were made from these isopropylic solutions, using phenol saturated with water as solvent for ascending chromatography in the presence of sodium cyanide and standard solutions of amino-acids for comparison.

Table 1 gives the amino-acids detected after irradiation of organic acid - ammonium salt mixtures.

Table 1. AMINO-ACIDS DETECTED AFTER 24 HR. EXPOSURE TO ULTRA VIOLET, $\lambda=2537 \mathrm{~A}$.

\begin{tabular}{|c|c|c|c|}
\hline \multirow[b]{2}{*}{ Mixture } & \multicolumn{3}{|c|}{ Amounts of amino-acids found } \\
\hline & $\begin{array}{c}\text { Aspartic } \\
\text { acid }\end{array}$ & Alanine & Glycine \\
\hline $\begin{array}{l}\text { Succinic acid and ammonia } \\
\text { Succinic acid and ammonium } \\
\text { carbonate } \\
\text { Succinic acid and ammonium } \\
\text { thiocyanate } \\
\text { Maleic acid and ammonium } \\
\text { carbonate } \\
\text { Propionic acid and ammon- } \\
\text { ium carbonate }\end{array}$ & +++ & $\begin{array}{c}++ \\
++ \\
+ \\
++\end{array}$ & $\begin{array}{l}+++ \\
+++\end{array}$ \\
\hline
\end{tabular}

Key : +++ very large, ++ large and + trace.

It must be concluded that ultra-violet, at a wave. length of $2537 \mathrm{~A}$., is able to synthesize amino-acids from mixtures containing either a saturated dicarboxylic acid such as succinic acid, an unsaturated. dicarboxylic acid such as maleic acid or a monocarboxylic acid such as propionic acid with carbonate or thiocyanate and ammonia.

The amino-acids are aspartic acid, alanine and glycine, that is to say, amino-acids with 4,3 and 2 carbon atoms respectively.

Only succinic acid gives an aliphatic aldehyde after irradiation.

A browning reaction occurs during the evaporation of the irradiated solutions, the intensity of which is dependent on the nature of the organic acid.
A full description of the results obtained in this field will be published later.

\section{A. R. Deschreider}

Central Laboratory,

Ministry of Economic Affairs, 23 rue Traversière,

Brussels 3. June 3.

\section{A Colorimetric Test for Gibberellic Acid and Evidence from a Dwarf Pea Assay for the Occurrence of a Gibberellin-like Substance in Wheat Seedlings}

A RECENT communication by McComb and Carr ${ }^{1}$, reporting the use of a dwarf pea bioassay for naturally occurring gibberellins, prompts this report of some results of an experiment designed to investigate whether gibberellic acid occurs naturally in etiolated wheat seedlings.

Wheat (var. Eclipse) was grown in darkness for four days at $25^{\circ} \mathrm{C}$. on moist filter paper contained in 11-cm. Petri dishes. In all, 12,500 coleoptiles with enclosed primary leaves were excised at $96 \mathrm{hr}$.; these were cut transversely into halves, representing the basal region, including the leaf meristem $(135 \mathrm{gm}$. fresh weight), and the tip (205 gm. fresh weight). Basal and tip sections were frozen separately to $-15^{\circ} \mathrm{C}$. in $2.5 \mathrm{l}$. of phosphate/citrate buffer of $p H \quad 3 \cdot 8$ and, after thawing, the tissue was filtered. Peroxide-free ether $(3 \cdot 3$ l.) was passed over the tissue and shaken with the filtrate in five aliquots. The resulting ether fraction was extracted with 4.41 . of 1 per cent sodium bicarbonate in five aliquots. This solution was then acidified to $p H 3.0$ with sulphuric acid and extracted five times with a total of $3 \cdot 3 \mathrm{l}$. of peroxide-free ether.

Each of the two acidic and neutral fractions was reduced to small volume and transferred, as a series of spots on the starting line, to $25.5 \mathrm{~cm}$. square Whatman No. 1 chromatography papers. Four sheets were used for each fraction. The chromatograms were developed by ascending chromatography, using the solvent system isopropanol/ammonia $(0 \cdot 880) /$ water $(10: 1: 1)$, the papers being removed when the solvent front had moved $23 \mathrm{~cm}$. Each sheet was cut horizontally into nine strips each $2.5 \mathrm{~cm}$. wide; these strips were then eluted with acetone, which in each case was concentrated to $2.5 \mathrm{ml}$. The thirty-six eluates were each transferred to $25.5 \mathrm{~cm}$. square Whatman No. 1 chromatography papers as a single spot for development in two directions in the solvent systems, (a) isopropanol/ ammonia $(0 \cdot 880) /$ water $(10: 1: 1) ;$ (b) n-butanol/ ammonia $(0 \cdot 880) /$ water $(200: 6: 36)$. In each case the solvent was allowed to move $23 \mathrm{~cm}$. Papers were dried between development in a current of air. Finally the papers were sprayed with Folin and Ciocalteau's ${ }^{2}$ reagent and kept in darkness for $4 \mathrm{hr}$. at $25^{\circ} \mathrm{C}$. I find that this reagent gives a characteristic colour with gibberellic acid.

When gibberellic acid, melting point $232-233 \cdot 5^{\circ} \mathrm{C}$. (decomposition), supplied by Imperial Chemical Industries, Ltd., was resolved in each of the above solvent systems and the chromatograms sprayed with this reagent two bright blue spots appeared as follows : (1) a dense blue spot, $R_{F}$ value 0.52 in system $(a)$ and 0.24 in system $(b)$; the material extracted from this position on the unsprayed paper was found to induce a growth response in dwarf 